\title{
Does Combine Thread Lifting with Liposuction Achieve Superior Outcomes Over Liposuction Alone for Neck Lipodystrophy?
}

\author{
MOHAMED S.M. HASSAN, M.D.* and WAEL NAEEM THABET GHEBERY, M.D.** \\ The Department of Plastic Surgery, Faculty of Medicine, Fayoum* and Cairo** Universities, Egypt
}

\begin{abstract}
Background: Aging of the neck is multifactorial with various skin changes. For an aesthetically pleasing neck appearance, it is critical restoring a cervicomental angle of 105 to 120 degrees, and a distinct mandibular border. A multimodality approach is required to rejuvenate the neck and address these multiple facets of aging. Many treatment options can be combined to address the aging changes of the neck.
\end{abstract}

Submental fat can be addressed by traditional or assisted liposuction. However, some patients with poor skin tone may not achieve optimal outcomes. Thread lifting is a minimally invasive, office-based procedure with fewer perioperative complications and gaining popularity as a substitute for surgical lifting.

Methods: This study aimed to answer whether combining thread-lift with traditional liposuction for rejuvenation of submental lipodystrophy will achieve a superior outcome in terms of patients' satisfaction and aesthetic results or no? To answer this question, the authors conducted a retrospective comparative study on all cases with submental lipodystrophy (known as 'double chin') who underwent neck rejuvenation by either liposuction alone as group $\mathrm{A}$, or liposuction combined with thread lifting as group B, to compare the results of both groups, and the subgroups based on the degree of neck lipodystrophy, in terms of patients' satisfaction and aesthetic results.

Results: The overall complication rate was $20 \%$ for group A and $25 \%$ for group B. However, there were no major complications in both groups.

While superior aesthetic results and patient satisfaction were obtained by combining liposuction and threading of cases with severe neck lipodystrophy, in cases of mild and moderate lipodystrophy no statistically significant difference was observed between both groups.

Conclusion: Combined liposuction and thread lifting is effective and gives superior aesthetic results and patient satisfaction more than liposuction alone in cases with severe lipodystrophy, especially for the cervicomental angle improvement. However, in mild and moderate cases of lipodystrophy, the additional thread-related complications, extra duration, and cost of thread lifting outweigh its benefits.

Key Words: Neck - Rejuvenation - Liposuction - Threading - Lift.

\section{INTRODUCTION}

The Aging of the neck is a multifactorial process with various skin changes. Thus, a multi-modality approach is required to rejuvenate the neck with the most optimal outcome by addressing these multiple facets of aging [1]. For an aesthetically pleasing neck appearance, it is critical restoring a cervicomental angle of 105 to 120 degrees, and a distinct mandibular border [2].

Accumulation of Submental fat leads to a more obtuse cervicomental angle and can age patients or make them look overweight. Submental fat can be addressed by traditional or assisted liposuction. However, some patients with poor skin tone may not achieve optimal outcomes [1].

Thread lifting is a minimally invasive office procedure with fewer perioperative complications and gaining popularity as a substitute for surgical lifting [3].

Non-absorbable barbed sutures are a suitable alternative for surgical techniques. However, it persists for a long time and might be easily palpable, or might extrude across the skin [4-8].

This study aimed to answer whether combining thread-lift with traditional liposuction for rejuvenation of submental lipodystrophy will achieve a superior outcome in terms of patients' satisfaction and aesthetic results or no?

\section{PATIENTS AND METHODS}

We conducted this retrospective comparative study on all cases with submental lipodystrophy (known as 'double chin') who underwent neck rejuvenation by either liposuction alone or liposuction combined with thread lifting.

After Patients' records were reviewed, we included all primary cases with moderate skin laxity (Grade 2 , and 2.5 on skin laxity grading scale described by 
Alexiades et al., [9]) presented with neck lipodystrophy who were medically fit, without medical comorbidity, and had followed-up for at least 6 months.

We excluded cases with advanced and severe skin laxity that are indicated only for surgical lifting or platysmoplasty (Grade 3 and 4 on skin laxity grading scale). To avoid side factors that might affect the results, we excluded all smokers, cases with medical co-morbidity or psychiatric illness, body mass index (BMI) over 40, and those with a history of neck rejuvenation or any treatment for neck lipodystrophy.
We divided patients, according to the procedure that was performed, into group A who underwent traditional liposuction only \& group B who underwent combined liposuction and thread lifting at the same time. Both groups were further divided, according to the degree of submental fat accumulation, into mild, moderate, and severe subgroups with the help of the Clinician-Reported Submental Fat Rating Scale (CRSMFRS) (Fig. 1) described by Mc Diarmid et al., after excluding grade " 0 " and combining grade " 3 " and grade " 4 " into severe cases for simplicity.



Fig. (1): Submental fat (SMF) grades. Adapted from Mc Diarmid J., Ruiz J.B., Lee D., et al., [10].

\section{Surgical technique:}

Informed consent was taken from all cases with preoperative digital photographs.

Preoperative markings relied on the chin, submental area, and the point of thread insertion with their directions.

All patients (group A \& B) underwent neck traditional liposuction after tissue tumescent and 3 areas were addressed: Central submental and bilateral jowls areas, to have a more defined youthful jaw line, with the manual evaluation of the skin thickness at the end of the procedure.

In group $\mathrm{B}$, besides liposuction, multidirectional Polydioxanone (PDO) barbed threads (Epiline 3 Dcog cannula $19 \mathrm{G}$ x $100 \mathrm{~mm}-15 \mathrm{~mm}$ ) were inserted, 4 on each side, in a fan-like pattern started from the angle of the mandible directed towards the midline. The PDO material was selected based on its economical price and easy manipulation compared with other thread types, and the treatment was performed following the manufacturer's recommended protocol.

Postoperatively, all patients applied pressure garments for 6 weeks. Patients followed up in the clinic on a weekly basis for the first month, then once monthly for 6 months postoperatively.

And all patients, with at least 6 months follow up, were asked to answer a patient satisfaction questionnaire using the Likert 5 points scale to detect patient's satisfaction response, and experience about: Per-operative pain, swelling, and bruises, improvement of each of cervicomental angle, mandibular contour, skin laxity, and submental fat 
deposits, the scar, increase of self-confidence, and overall experience and recommending procedures to others. All preoperative and postoperative photos were blindly assessed by five plastic surgeons focusing on the improvement of cervicomental angle, visual accumulation of submental fat, mandibular contour, and improvement of visible skin laxity using the Global Aesthetic Improvement Scale (GAIS) which is a five-point relative improvement scale described by De Lorenzi et al., [11].

Data collected for each patient included age, body mass index (BMI), and the degree of lipodystrophy (mild, moderate, or severe), duration of the procedure, complications, patient's questionnaire responses, and assessors' average GAIS scores.

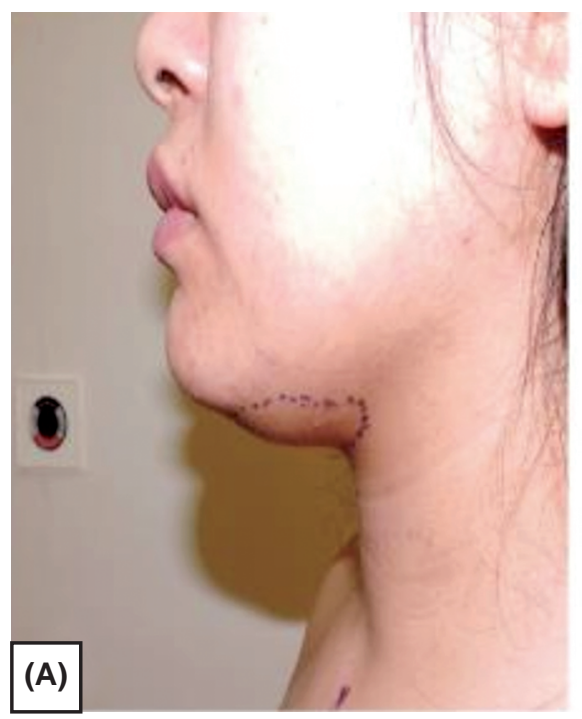

Photo (1): Mild lipodystrophy (A) Before and (B) After liposuction.
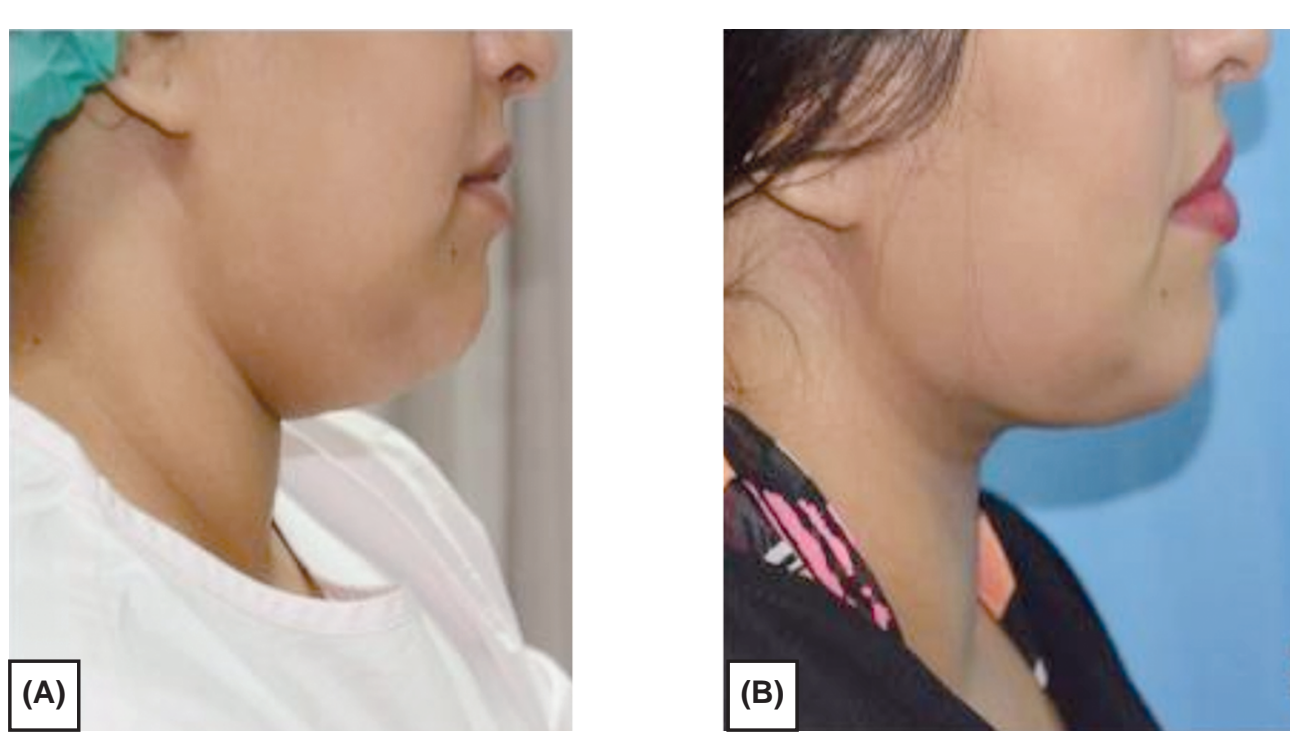

Photo (2): Moderate lipodystrophy (A) Before and (B) After liposuction. Mann-Whitney test.

\section{RESULTS} 5 cases in group B).

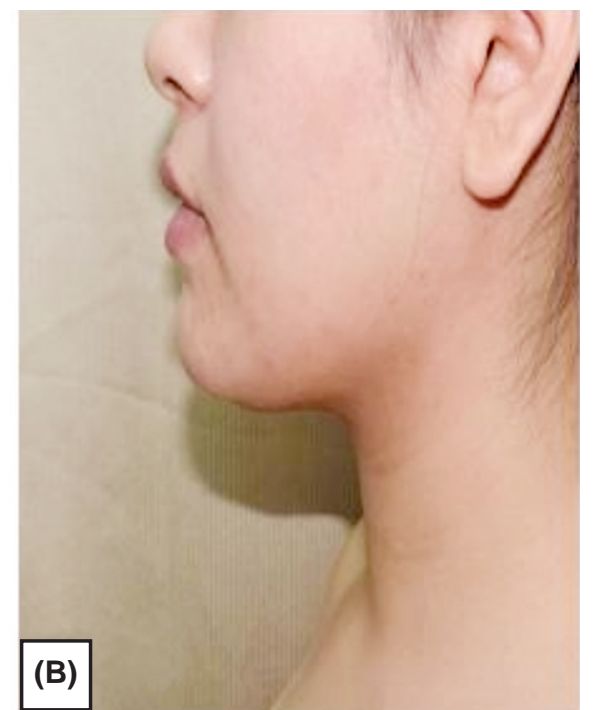

All data were tabulated, and non-parametric data of both groups were compared and statistically analyzed for the significant difference using the

Some patients' photos are represented in Photos (1-6). The number of valid cases was 40 primary cases who underwent neck rejuvenation by either liposuction alone (group A, 20 cases) or combined treatment with liposuction and thread lifting (group B, 20 cases). Groups were further sub-grouped according to the degree of submental fat into mild ( 6 cases in group A, and 7 cases in group B), moderate ( 8 cases in each of group $A$, and group B), and severe subgroups (6 cases in group A, and 
Photo (3): Severe lipodystrophy (A) Before and (B) After liposuction.
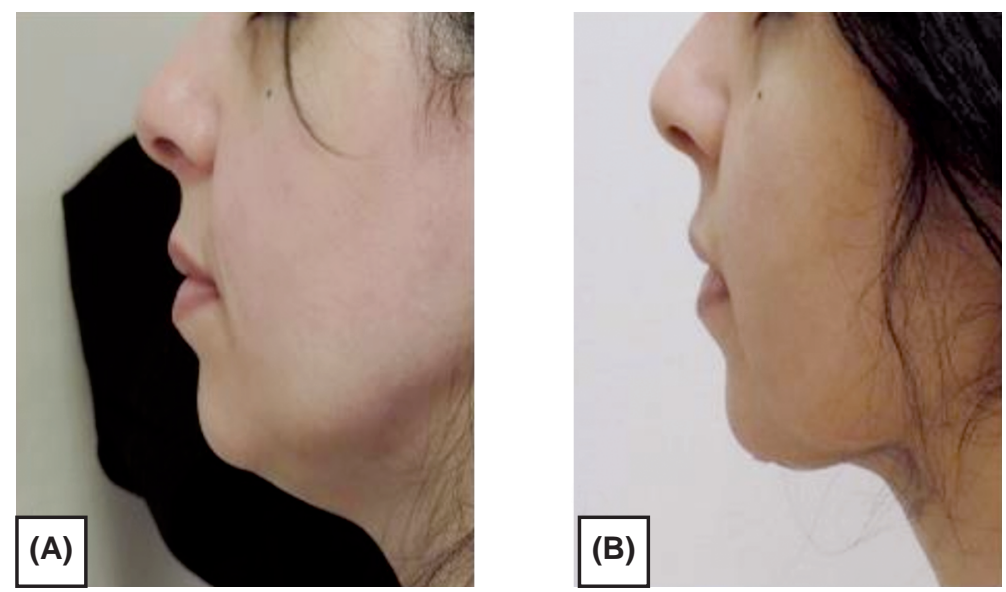

Photo (4): Mild lipodystrophy before (A) and after (B) Combined liposuction and threading.

Photo (5): Moderate lipodystrophy before (A) and after (B) Combined liposuction and threading.

Photo (6): Severe lipodystrophy before (A) and after (B) Liposuction and threading.
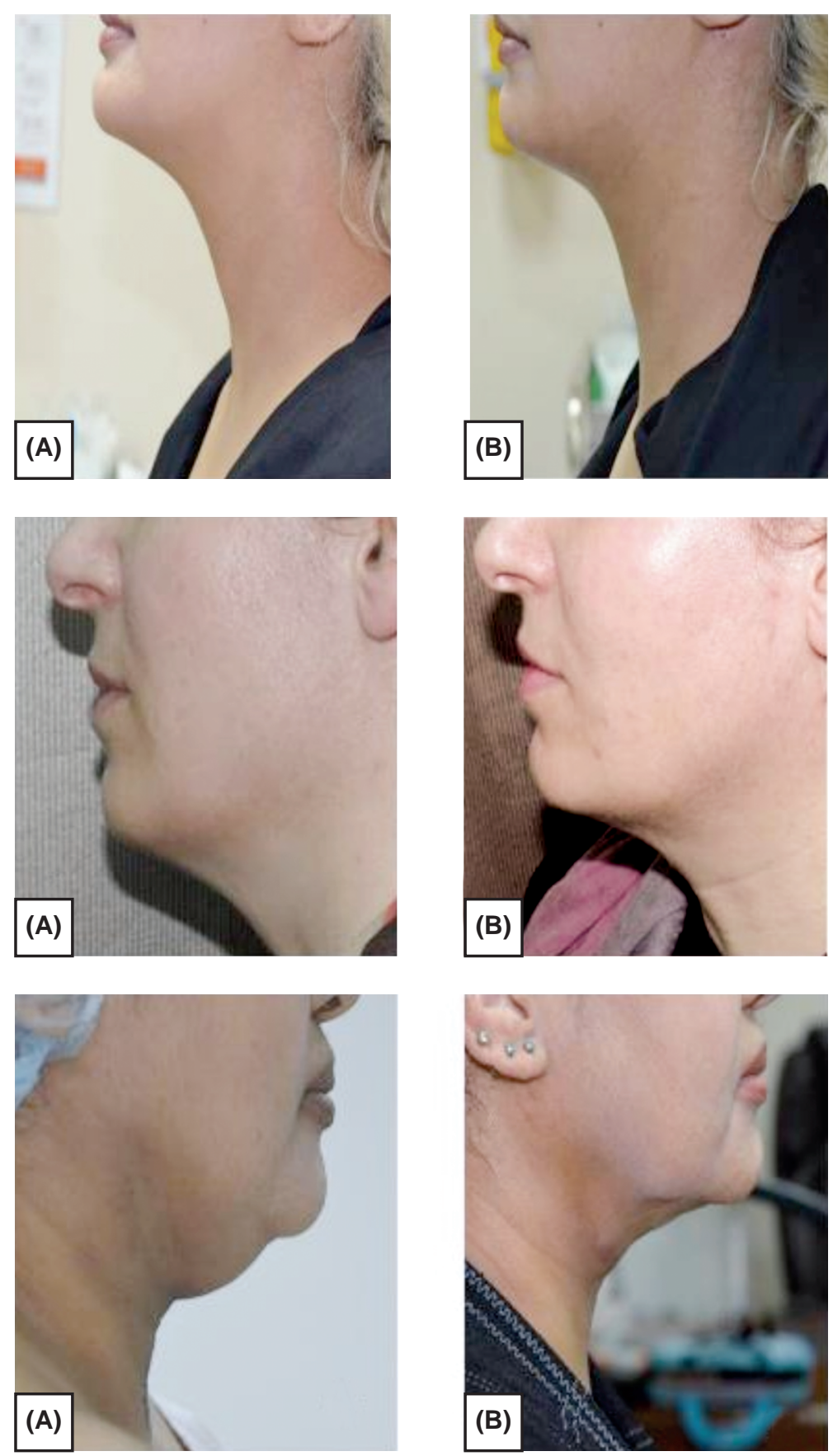
All patients were female. For group A, age ranged between 33 and 50 years (mean 41.7 years). While, in group B, age ranged between $32-50$ years (mean 42.05 years) with no statistical difference between both groups $(p=0.85)$.

The BMI ranged between 25 and 30 (mean 27.05) for group A and ranged between 25 and 30 (mean 27.55) for group B ( $p=0.38)$.

The operative time for group A ranged between 25-39 minutes (mean 32.25 minutes). The operative time for group B ranges between 87 and 102 minutes (mean 95.05 minutes). Group B was longer than group A $(p=0.01)$.

The amount of fat aspirated in group A ranged between 36 and $89 \mathrm{ml}$ (mean $63.7 \mathrm{ml}$ ). The amount of fat aspirated in group B ranged between 38 and $92 \mathrm{ml}$ (mean $64.2 \mathrm{ml}$ ).

No statistical difference between both groups' amount of aspirated fat $(p=0.75)$.

The overall complication rate was $20 \%$ for group A, and $25 \%$ for group B. However, there were no major complications in both groups. One case of each group developed postoperative prolonged edema and bruising ( $>2$ weeks) which were treated conservatively by extended skin massage. 2 cases of each group developed prolonged sensory changes in the form of numbness which persist for over 6 months. Only in group B, thread related complications detected in the form of 2 cases developed thread break in the first week and treated successfully with simple reinsertion of threads. 2 cases developed palpable and visible threads which lasted for 6 weeks and were treated with reassurance and patients were satisfied with the overall result.

The mean satisfaction score of group A was 4.54 , and group B was 4.70. With no statistical difference between both groups $(p=0.20)$. The mean GAIS of group A was 3.24, and group B was 3.44. With no statistical difference between both groups $(p=0.13)$.

On further analysis of subgroups based on the degree of submental fat, it was found that:

For mild cases, the mean satisfaction of group A was significantly higher than group B (satisfaction scores were 4.73 for group A and 4.47 for group B with $p=0.008$ ).

The average GAIS for mild cases was 3.29 for group A and 3.21 for group B, with no statistical significance between both groups $(p=0.88)$. Patients expressed no statistically significant different responses except for improvement of post-operative swelling $(p=0.04)$ and skin laxity $(p=0.03)$. Their answers about the improvement of submental swelling revealed a higher score for group A (5) compared with group B (4.1) $(p=0.04)$. The responses about skin laxity improvement were statistically higher in group A (score 5) than group B (score 4.4) $(p=0.03)$ But No statistical difference between both groups' assessors GAIS scores.

For moderate cases of lipodystrophy, the mean satisfaction rate was statistically significantly higher for group B (4.75) than for group A (4.31) $(p=0.007)$. Specifically, patients' responses were higher for group B than group B for the accumulation of submental fat (group $A=4.1$, group $B$ $=4.9$, and $p=0.014$ ), the skin laxity (group $\mathrm{A}=4.1$, group $\mathrm{B}=5$, and $p=0.003$ ), contouring of the mandible (group $\mathrm{A}=4.1$, group $\mathrm{B}=5$, and $p=0.001$ ), overall experience (group $\mathrm{A}=4.16$, group $\mathrm{B}=4.59$, and $p=0.009$ ), and average satisfaction (group $\mathrm{A}=4.13$, group $\mathrm{B}=4.75$, and $p=0.007$ ). While the average GAIS was 3.28 for group A and 3.38 for group $\mathrm{B}(p=0.62)$ with no statistical significance in any of the assessors' scores between both groups.

For severe cases of lipodystrophy, it was found that the mean satisfaction rate was statistically significantly higher for group B (4.92) than for group A (4.65) $(p=0.04)$. Especially the improvement of the cervicomental angle, which was statistically higher in group B (5) than group A (4.3) $(p=0.03)$. Also, the average GAIS of group A was 3.13 and of group B was $3.85(p=0.005)$. The assessors' scores were especially higher in group $B$ than in group A for: Improvement of Cervicomental Angle group A (3.2) and group B (4) $(p=0.01)$ and visible submental fat accumulation which was 3.2 for group A and 4 for B $(p=0.01)$.

Table (1): Comparison between Group A and B patients' demographics.

\begin{tabular}{lccc}
\hline & Group & Mean & $p$-value \\
\hline Age (years) & A & 41.70 & 0.85 \\
& B & 42.05 & \\
Body Mass Index (BMI) & A & 27.05 & 0.38 \\
& B & 27.55 & \\
Procedure Duration (minutes) & A & 32.25 & 0.01 \\
& B & 95.05 & \\
Amount of collected fat (ml) & A & 63.7 & 0.75 \\
& B & 64.2 & \\
\hline
\end{tabular}


Table (2): Comparison between Group A and B means of patient satisfaction responses.

\begin{tabular}{llllcccccccc}
\hline Group & Pain & Swelling & Scar & $\begin{array}{c}\text { Submental } \\
\text { fat }\end{array}$ & Laxity & $\begin{array}{c}\text { Cervicomental } \\
\text { angle }\end{array}$ & $\begin{array}{c}\text { Mandibular } \\
\text { contour }\end{array}$ & Bruises & Confidence $\begin{array}{c}\text { Overall } \\
\text { experience }\end{array}$ & $\begin{array}{c}\text { Average } \\
\text { score }\end{array}$ \\
\hline A & 4.11 & 4.57 & 5.00 & 4.65 & 4.69 & 4.26 & 4.49 & 4.72 & 4.53 & 4.36 & 4.54 \\
B & 4.22 & 4.56 & 4.95 & 4.82 & 4.81 & 4.60 & 4.81 & 4.79 & 4.77 & 4.48 & 4.70 \\
$p$-value & 0.903 & 0.602 & 0.317 & 0.265 & 0.294 & 0.09 & 0.024 & 0.541 & 0.107 & 0.173 & 0.20 \\
\hline
\end{tabular}

Table (3): Comparison between Group A and B means of assessors' average GAIS scores.

\begin{tabular}{lccccc}
\hline Group & $\begin{array}{c}\text { Widening of } \\
\text { the cervicomental } \\
\text { angle }\end{array}$ & $\begin{array}{c}\text { Loss of } \\
\text { the mandibular } \\
\text { contour }\end{array}$ & $\begin{array}{c}\text { Accumulation of } \\
\text { submental fat }\end{array}$ & $\begin{array}{c}\text { Visible skin } \\
\text { laxity }\end{array}$ & $\begin{array}{c}\text { Average } \\
\text { assessment }\end{array}$ \\
\hline A & 3.33 & 3.24 & 3.36 & 3.00 & 3.23 \\
B & 3.60 & 3.60 & 3.55 & 3.18 & 3.48 \\
$p$-value & 0.209 & 0.167 & 0.415 & 0.075 & 0.133 \\
\hline
\end{tabular}

Table (4): Comparison between Group A and B, with mild SMF, patients' mean satisfaction responses.

\begin{tabular}{llllllllllll}
\hline Group & Pain & Swelling & Scar & SM fat & Laxity & CM angle & Contour & Bruises & Confidence & $\begin{array}{c}\text { Overall } \\
\text { experience }\end{array}$ & $\begin{array}{c}\text { Average } \\
\text { scores }\end{array}$ \\
\hline A-mild & 3.83 & 5.00 & 5.00 & 5.00 & 5.00 & 4.33 & 4.67 & 5.00 & 4.83 & 4.46 & 4.73 \\
B-mild & 4.00 & 4.14 & 4.86 & 4.57 & 4.43 & 4.29 & 4.43 & 5.00 & 4.57 & 4.11 & 4.47 \\
$p$-value & 0.938 & 0.035 & 0.355 & 0.079 & 0.033 & 0.859 & 0.409 & 1 & 0.327 & 0.409 & 0.008 \\
\hline
\end{tabular}

Table (5): Comparison between Group A and B, with mild submental fat (SMF), means of assessors, GAIS scores.

\begin{tabular}{lccccc}
\hline Group & $\begin{array}{c}\text { Widening of } \\
\text { the cervicomental } \\
\text { angle }\end{array}$ & $\begin{array}{c}\text { Mandibular } \\
\text { contour }\end{array}$ & $\begin{array}{c}\text { Accumulation of } \\
\text { submental fat }\end{array}$ & $\begin{array}{c}\text { Visible skin } \\
\text { laxity }\end{array}$ & $\begin{array}{c}\text { Average } \\
\text { assessment }\end{array}$ \\
\hline A-mild & 3.33 & 3.17 & 3.67 & 3.00 & 3.29 \\
B-mild & 3.29 & 3.43 & 3.14 & 3.00 & 3.21 \\
$p$-value & 0.859 & 0.485 & 0.269 & 1 & 0.884 \\
\hline
\end{tabular}

Table (6): Comparison between Group A and B, with moderate SMF, means of patients' satisfaction responses.

\begin{tabular}{llllllllllll}
\hline Group & Pain & Swelling & Scar & Fat & Laxity & Angle & Contour & Bruises & Confidence & $\begin{array}{c}\text { Overall } \\
\text { experience }\end{array}$ & $\begin{array}{c}\text { Average } \\
\text { scores }\end{array}$ \\
\hline A-moderate & 4.00 & 4.38 & 5.00 & 4.13 & 4.25 & 4.13 & 4.13 & 4.50 & 4.25 & 4.16 & 4.31 \\
B-moderate & 4.25 & 4.75 & 5.00 & 4.88 & 5.00 & 4.50 & 5.00 & 4.38 & 4.75 & 4.59 & 4.75 \\
$p$-value & 0.464 & 0.519 & 1 & 0.014 & 0.003 & 0.232 & 0.001 & 0.814 & 0.053 & 0.009 & 0.007 \\
\hline
\end{tabular}

Table (7): Comparison between Group A and B, with moderate SMF, means of assessors GAIS scores.

\begin{tabular}{lccccc}
\hline Group & $\begin{array}{c}\text { Widening of } \\
\text { the cervicomental } \\
\text { angle }\end{array}$ & $\begin{array}{c}\text { Mandibular } \\
\text { contour }\end{array}$ & $\begin{array}{c}\text { Accumulation of } \\
\text { submental fat }\end{array}$ & $\begin{array}{c}\text { Visible skin } \\
\text { laxity }\end{array}$ & $\begin{array}{c}\text { Average } \\
\text { assessment }\end{array}$ \\
\hline A-moderate & 3.50 & 3.38 & 3.25 & 3.00 & 3.28 \\
B-moderate & 3.50 & 3.38 & 3.50 & 3.13 & 3.38 \\
$p$-value & 1 & 0.86 & 0.637 & 0.317 & 0.619 \\
\hline
\end{tabular}


Table (8): Comparison between Group A and B, with severe SMF, means of patient satisfaction responses.

\begin{tabular}{llclllllllll}
\hline Group & Pain & Swelling & Scar & Fat & Laxity & Angle & Contour & Bruises & Confidence & $\begin{array}{c}\text { Overall } \\
\text { experience }\end{array}$ & $\begin{array}{c}\text { Average } \\
\text { scores }\end{array}$ \\
\hline A-severe & 4.50 & 4.33 & 5.00 & 4.83 & 4.83 & 4.33 & 4.67 & 4.67 & 4.50 & 4.46 & 4.65 \\
B-severe & 4.40 & 4.80 & 5.00 & 5.00 & 5.00 & 5.00 & 5.00 & 5.00 & 5.00 & 4.75 & 4.92 \\
$p$-value & 0.752 & 0.56 & 1 & 0.361 & 0.361 & 0.029 & 0.174 & 0.174 & 0.077 & 0.361 & 0.04 \\
\hline
\end{tabular}

Table (9): Comparison between Group A and B, with severe SMF, means of assessors GAIS scores.

\begin{tabular}{lccccc}
\hline Group & $\begin{array}{c}\text { Widening of } \\
\text { the cervicomental } \\
\text { angle }\end{array}$ & $\begin{array}{c}\text { Mandibular } \\
\text { contour }\end{array}$ & $\begin{array}{c}\text { Accumulation of } \\
\text { submental fat }\end{array}$ & $\begin{array}{c}\text { Visible skin } \\
\text { laxity }\end{array}$ & $\begin{array}{c}\text { Average } \\
\text { assessment }\end{array}$ \\
\hline A-severe & 3.17 & 3.17 & 3.17 & 3.00 & 3.13 \\
B-severe & 4.00 & 4.00 & 4.00 & 3.40 & 3.85 \\
$p$-value & 0.008 & 0.032 & 0.008 & 0.102 & 0.005 \\
\hline
\end{tabular}

\section{DISCUSSION}

For an aesthetically pleasing appearance, it is critical restoring a youthful neck with aesthetically pleasing criteria including a cervicomental angle of 105 to 120 degrees, a distinct mandibular border, a visible anterior border of the sternocleidomastoid, a subhyoid depression, and bulging thyroid cartilage [2].

Unfortunately, many factors contribute to the aging of the neck, including submental fat accumulation which leads to a more obtuse cervicomental angle and makes patients appear older or overweight. Thus, rejuvenation of the neck is ideally achieved by a multi-modality approach to address these multiple facets of aging [1].

Although liposuction removes large amounts of unwanted fat, it is recommended to be combined with other treatment modalities to improve outcomes efficiently and skin tightening, especially for patients with poor skin tone who may not achieve optimal outcomes $[\mathbf{1 , 1 2 , 1 3 ]}$.

Minimally invasive techniques are quick, officebased procedures, and with fewer perioperative complications. The minimally invasive thread lifting became a preferred substitute for surgical lifting [3]. Despite the duration of the procedure in group B was longer than group A, this is clinically expected because of the additional procedure time added in group B.

In this study, we compared the results, patients' satisfaction, and aesthetic outcomes, of both traditional liposuction and combined liposuction \& threading to address the problem of submental fat accumulation.
Some thread lifts patients suffer from palpable and visible threads under the skin shortly after the procedure, especially with thin skin. Surgeons should carefully insert threads at the optimum depth [13]. And this may explain the longer duration difference between both groups (60 minutes difference in mean duration) which is required for precise placement of all threads at optimum level in the thinned skin post-liposuction. Despite all care and precision of placement of threads, 2 cases in this study developed palpable and visible threads under the skin and managed by reassurance and conservative massage.

A lack of sensitivity or numbness in the treated area may happen [14] and usually resolve within weeks of the procedure. We detected this in 4 cases of this study, and it was managed conservatively and completely resolved.

Migration or even total extrusion of the thread or thread breaks may cause an unbalanced facial appearance [14], which was detected in 2 cases of our study; however, it is simply managed by reinsertion of a new thread in the office.

Apart from their mechanical lifting effect, the threads also have histological rejuvenating effects. Kapicioglu et al., [15] in their experimental study, on both COG PDO threads and poly L Lactic acid (PLLA) threads, found that both types of the threads significantly increased dermal thickness, fibroblasts population, and enhanced collagen production compared with the control group, with an initial delay of the COG threads. However, there was no statistical difference between the COG and PLLA groups after 6 months, and the threads in both groups were completely dissolved after 6 months. 
In the PLLA group, there were initial intense inflammatory infiltration and minimal scaring followed by late decrease inflammatory infiltrate and increased scaring. In this study, where the patients were expected to have a complimentary lift surgery in case of failure of thread lift, the PDO threads were preferred over the PLLA threads because of their relatively shorter duration of action and more economical price.

On comparing the data of both groups there was no statistical difference between group A and group B average patients' satisfaction scales or assessors average GAIS scores. However, the analysis of the subgroups showed that:

For mild cases, the mean satisfaction rate was statistically significantly higher for group A than for group B, especially for the improvement of skin swelling and skin laxity. However, this did not meet with any statistically significant difference between both groups' average of assessors' GAIS scores. This may reflect a placebo effect rather than a superior clinical outcome.

For moderate cases of lipodystrophy, the mean satisfaction rate was statistically significantly higher in group B than in group A, especially Patients' responses about the accumulation of submental fat, skin laxity, mandibular contour, and overall experience. However, this also did not meet any statistically significant difference between both groups' average of assessors' GAIS scores. This may reflect a placebo effect rather than a real clinical improvement of the outcomes.

However, in the severe cases of lipodystrophy, it was found that the mean patients' satisfaction scales for group B were statistically significantly higher than group A, especially for the improvement of the cervicomental angle. This was also confirmed with statistically significantly higher group B than group A's assessors GAIS scores, especially for Cervicomental Angle and visual submental fat accumulation. This can be explained by the thread lifting effect masking the skin redundancy following the liposuction with more flattening of the submental curve giving the visual effect of less submental fat accumulation.

\section{Conclusion:}

Combined liposuction and thread lifting is effective and gives superior aesthetic results and patient satisfaction more than liposuction alone in cases with severe lipodystrophy, especially for the cervicomental angle improvement. However, in mild and moderate cases of lipodystrophy, the additional thread-related complications, extra duration, and cost of thread lifting outweigh its benefits.

\section{Conflict of interest:}

No conflict of interest or financial support to be disclosed.

\section{REFERENCES}

1- Vanaman M., Fabi S. and Cox S.: Neck Rejuvenation Using a Combination Approach: Our Experience and a Review of the Literature. Dermatol Surg [Internet]. May [cited 2019 Dec. 10]; 42. Available from: insights. ovid.com, 2016.

2- Ellenbogen R. and Karlin J.V.: Visual criteria for success in restoring the youthful neck. Plast. Reconstr. Surg., Dec. 66 (6): 826-37, 1980.

3- Abraham R.F., DeFatta R.J. and Williams E.F.: Threadlift for Facial Rejuvenation: Assessment of Long-term Results. Arch. Facial Plast. Surg., May 1; 11 (3): 178-83, 2009.

4- Isse N.G., Fodor P.B.: Elevating the midface with barbed polypropylene sutures. Aesthet. Surg. J., Jun. 25 (3): 3013, 2005 .

5- Sulamanidze M.A., Paikidze T.G., Sulamanidze G.M., Neigel JM. Facial lifting with "APTOS" threads: Featherlift. Otolaryngol. Clin. North Am., Oct. 38 (5): 110917, 2005.

6- Horne D.F. and Kaminer M.S.: Reduction of face and neck laxity with anchored, barbed polypropylene sutures (Contour Threads). Skin Ther. Lett., Feb. 11 (1): 5-7, 2006.

7- Ruff G.: Technique and uses for absorbable barbed sutures. Aesthet. Surg. J., Oct. 26 (5): 620-8, 2006.

8- Khiabanloo S.R., Jebreili R., Aalipour E., Saljoughi N. and Shahidi A.: Outcomes in thread lift for face and neck: A study performed with Silhouette Soft and Promo Happy Lift double needle, innovative and classic techniques. J. Cosmet Dermatol., 18 (1): 84-93, 2019.

9- Alexiades-Armenakas M., Rosenberg D., Renton B., Dover J. and Arndt K.: Blinded, randomized, quantitative grading comparison of minimally invasive, fractional radiofrequency and surgical face-lift to treat skin laxity. Arch. Dermatol., Apr. 146 (4): 396-405, 2010.

10- McDiarmid J., Ruiz J.B., Lee D., Lippert S., Hartisch C. and Havlickova B.: Results from a Pooled Analysis of Two European, Randomized, Placebo-Controlled, Phase 3 Studies of ATX-101 for the Pharmacologic Reduction of Excess Submental Fat. Aesthetic Plast. Surg., Oct. 38 (5): 849-60, 2014.

11- Delorenzi C., Weinberg M., Solish N. and Swift A.: A Multicenter Study of the Efficacy and Safety of Subcutaneous Nonanimal Stabilized Hyaluronie Acid in Aesthetic Facial Contouring: Interim Report: SUBCUTANEOUS RESTYLANE. Dermatol. Surg. Mar. 15; 32 (2): 205-11, 2006.

12- Goldman A.: Submental Nd:Yag laser-assisted liposuction. Lasers Surg. Med., Mar. 38 (3): 181-4, 2006. 
13- Woodhall K.E., Saluja R., Khoury J. and Goldman M.P.: A comparison of three separate clinical studies evaluating the safety and efficacy of laser-assisted lipolysis using $1,064,1,320 \mathrm{~nm}$, and a combined 1,064/1,320 nm multiplex device. Lasers Surg. Med., Dec. 41 (10): 774-8, 2009.

14- Kalra R.: Use of barbed threads in facial rejuvenation.
Indian J. Plast. Surg. Off Publ Assoc. Plast. Surg. India., Oct. 41 (Suppl): S93-100, 2008.

15- Kapicioğlu Y, Gül M, Saraç G, Yiğitcan B. and Gözükara H.: Comparison of Antiaging Effects on Rat Skin of Cog Thread and Poly-1-Lactic Acid Thread. Dermatol. Surg., Mar. 45 (3): 438-45, 2019. 